\title{
cc creative
}

BY-NC-SA 4.0

UMÁTICA. Revista sobre Creación y Análisis de la Imagen

\{ISSN: 2659-5354// D.L.: MA- 1628-2018\}

\section{Hacia una fenomenología de lo inmanentemente invisible}

Towards a phenomenology of the immanently unseeable

\section{GASTON GIRIBET (10 0000-0001-7654-6358}

Universidad de Buenos Aires FCEyN-UBA y CONICET, Argentina.

\section{Resumen}

Abordamos el problema de cómo pensar una fenomenología de lo invisible, entendido este término en un sentido fuerte: Se trata aquí de una invisibilidad inmanente, la de la ausencia, la de lo subjuntivo. Investigamos en qué medida está lo invisible relacionado con la ausencia, cómo es tomar consciencia de esa ausencia y proyectar sentido a partir de ella. Nos valemos para esto de avances recientes en el campo de la astrofísica: la "observación" de objetos de la naturaleza que realizan, en efecto, lo inmanentemente invisible; objetos que quedan definidos por la ausencia del mismo espacio-tiempo en el que son.

PALABRAS CLAVE: Fenomenología, filosofía de la ciencia, agujeros negros, imagen, horizontes.

Artículo original

Original Article

Correspondencia/ Correspondence Gaston Giribet giribet@gmail.com, gaston@df.uba.ar

Financiación/Fundings Sin financiación

Received: $13 \cdot 10.2020$ Accepted: 29.12 .2020

CÓMO CITAR ESTE TRABAJO / HOW TO CITE THIS PAPER

Giribet, G. (2020). Hacia una fenomenología de lo inmanentemente invisible. Umática. Revista sobre Creación y Análisis de la Imagen, 3 .

https://doi.org/10.24310/Umatica.2020.v2i3.10385

Umática. 2020; 3:15-29 


\title{
Hacia una fenomenología de lo inmanentemente invisible
}

\section{GASTON GIRIBET}

Universidad de Buenos Aires FCEyN-UBA y CONICET, Argentina.

\begin{abstract}
We tackle the problem of how to think of a phenomenology of the unseeable, understanding this term in a strong sense: It is about an immanent invisibility, that of absence, that of the subjunctive. We investigate to what extent the unseeable is related to absence, what does it mean to become aware of that absence, and to project meaning out from it. To this, we make use of recent advances in the field of astrophysics: the "observation" of objects in nature that make, in fact, the immanently invisible; objects that are defined by the absence of the very space-time in which they are.
\end{abstract}

KEYWORDS: Phenomenology, philosophy of science, black holes, image, horizons.

Summary - Sumario

1. Introducción

2. El espaciotiempo, el objeto, su ausencia

3. La ausencia y la fenomenología de lo invisible

4. Sobre la imagen y su horizonte

5. El objeto teleológico 


\section{Introducción}

Si el fenómeno es aquello que surge de lo oculto y entra en el ámbito de lo visible, ¿cómo es posible pensar lo inmanentemente invisible desde la fenomenología? ¿Cuánto esfuerzo debemos exigirle a nuestra definición de "lo visible" para poder pensar en términos fenomenológicos a aquello que se encuentra a medio camino entre lo que no puede ser visto y lo que está ausente? Si bien cae de suyo que "entrar en el ámbito de lo visible" funciona aquí como figura retórica, una imagen potente de contenido simbólico, convendremos que, como toda figura retórica, no es casual. Es así como resiste la pregunta sobre la manera de abordar la invisibilidad, en cuanto cualidad inmanente, con el método fenomenológico. Esta invisibilidad inmanente a la que nos referimos es la invisibilidad de la ausencia, la de lo subjuntivo y la de los fenómenos elusivos emparentados.

Este es el problema del que nos ocuparemos aquí: Cómo pensar una fenomenología de lo invisible, entendido este término en un sentido fuerte, y en qué medida está lo invisible relacionado con la ausencia. Cómo es tomar consciencia de esa ausencia y, así, proyectar sentido a partir de ella. Bien lo expresaba Levinas: "La invisibilidad no indica ausencia de relación: implica relaciones con lo que no está dado, con aquello de lo que no hay idea" (2006, p. 28).

Pero, para evitar confusiones, comencemos por una cuestión terminológica que será central: Con invisible no nos referiremos aquí a un objeto al que por contingencia es imposible ver, no es el "in-visible visible" de Derrida (2000, p. 88), sino a un objeto que está definido por su imposibilidad de ser visto. Se trata, decíamos, de una invisibilidad inmanente. No hablaremos aquí de la naturaleza de lo invisible, sino de lo invisible en la naturaleza. Este invisible, como adelantábamos, se encuentra en tránsito entre lo que no puede ser visto y lo que está ausente, y debe esta ausencia ser entendida, también, en un sentido fuerte, por cuanto es ausencia del espacio (тómoৎ) en el cual el objeto es². Hablamos de entes que están definidos por sus horizontes; que son sus horizontes.

[L]o propio de la percepción es que el objeto no aparezca más que en una serie de perfiles, de proyecciones. [...] El objeto mismo es la síntesis de todas estas apariciones. [...] Estoy en el centro de mi idea, la aprehendo por entero de una sola vez. Lo que naturalmente no quiere decir que mi idea no tenga que ser completada con un progreso infinito (Sartre, 2005, p. 23).

1. Lugar en el sentido estricto del то́тоৎ sobre el que habla Aristóteles en su libro IV de Física. Grosseteste, en su "Suma de los ocho libros de la física de Aristóteles", resumiendo un argumento del libro cuarto acerca del тómos, parafrasea: "Omne quod est, est in loco" (Todo cuanto existe está en un lugar).

2. En la sección 2 daremos una definición precisa de los objetos a los que nos referimos y quedará claro en qué sentido se habla aquí de "la ausencia del espacio en la que el objeto es".

Umática. 2020; 3:15-29 
Sin una definición precisa de los objetos específicos a los que nos referiremos, definición que postergaremos hasta la sección 2, podemos intentar ir acercándonos a la idea proponiendo ejemplos de objetos que, al igual que la ausencia, quedan definidos sólo por sus horizontes. Podemos pensar, por ejemplo, en el lienzo vacío al que aludía Kandinsky, que, "en apariencia, está verdaderamente vacío y guarda silencio; pero en realidad está lleno de tensiones, con mil voces bajas, llenas de espera" (1987, p. 127). Deleuze piensa en una potencialidad similar: "Una tela no es una superficie blanca. [...] Esas cosas invisibles, sin embargo, que ya han tomado la tela" (2007, p. 34). Pero los objetos de los que hablamos aquí son de una naturaleza diferente: Al igual que al lienzo vacío, sus horizontes los definen, sí, pero no es ésa su única característica: No hay datos de sensación que provengan de ellos en cuanto substancia [no son substancia]. Sabemos de ellos sólo por su influencia en el entorno, por su relación con lo circundante, por sus horizontes externos. Sus horizontes internos, por otro lado, plantean una dificultad mayor: Ningún escorzo nos es dado. Todos ellos son invisibles. El espacio que estos objetos ocupan está ausente [no son en el espacio ${ }^{3}$. Existe, sin embargo, esa ausencia, la del espacio que ocupan; una ausencia dinámica; la ausencia del tóroç. Es a dicha ausencia a la que debemos dirigir la mirada y a la que debemos dar sentido.

Para acercarnos un poco más a la definición de estos entes, adjetivémoslos adecuadamente. Para ello, tomemos prestado del inglés un término conveniente: the unseeable, una sustantivación que es de una gravedad mayor a the invisible. El castellano, a menudo exiguo en matices, nos impone el segundo de estos términos, pero es en el sentido del primero que debemos entender aquí lo invisible. No es casual que Sheperd Doeleman haya elegido dicha palabra para expresar la vivencia de haberse enfrentado a uno de esos entes por primera vez: the unseeable, lo que no es posible de ser visto, y no por una imposibilidad contingente de interactuar con la luz, sino por su propia definición, por su naturaleza, su фuбıkńc.

Quizá convenga reiterar aquí una advertencia que arriba hicimos al pasar: La distinción entre lo contingentemente invisible y lo invisible en sentido fuerte (unseeable) con la que trataremos aquí no es aquella distinción que hace Derrida (2000, p. 89) entre lo in-visible visible y lo que él y otros llaman la invisibilidad absoluta (Cfr. Hernández-Navarro, 2012 p. 16). Para Derrida, lo in-visible visible es aquello que es del orden de lo visible pero que se mantiene secreto sustrayéndolo a la vista [contingencia], mientras que lo absolutamente no visible es todo cuanto no se refiere al registro de la vista, pensando en lo sonoro como ejemplo cabal. Los objetos a los que aquí nos referiremos como unseeable no son ese "absolutamente no visible" sino objetos cuya invisibilidad es de una inmanencia mayor por cuanto termina definiéndolos. La voz, lo sonoro, no es tan solo sus horizontes, no sufre de la ausencia de datos de sensación. De suerte que el acto de transducción al observar lo sonoro no involucre a la luz. No deja lo sonoro de ser substancia y menos deja el espacio en el que lo sonoro es de estar presente. La inmanencia de la invisibilidad de lo que aquí preferimos llamar unseeable es, como veremos, de un grado mayor. Aunque también de carácter ontológico y relacionada con la ausencia, debemos diferenciar esta invisibilidad de otras consideradas por fenomenólo-

3. Y así como no son en el espacio, no son en el tiempo. Discutiremos esto en la sección IV.

Umática. 2020; 3:15-29 
gos. Quizá la más radical es la de Michel Henry, quien asocia la dimensión de lo invisible con la ausencia del mundo en el que las cosas se nos dan:

El ser no es, pues, una noción unívoca. Dos dimensiones lo atraviesan y vienen a desgarrar su unidad primitiva [...]: la de lo visible, donde la luz del mundo las cosas se dan a nosotros y son vividas por nosotros como fenómenos exteriores; la de lo invisible, donde, en ausencia de ese mundo y de su luz, antes incluso de que surgiese ese horizonte de exterioridad que pone todo a cierta distancia de nosotros y nos lo pro-pone a título de objeto [...], la vida se ha apoderado ya de su ser propio, abrazándose a sí misma en esa prueba interior e inmediata de sí que es su pathos, que hace de ella la vida. (Henry, 2008, p. 19)

Dado que decimos de los objetos que queremos tratar aquí que son ellos la propia ausencia del espacio en el que son, debemos plantear primero la cuestión de la ausencia como fenómeno: ¿Puede la ausencia ser pensada como fenómeno? Sartre es enfático al responder: "Sin duda, se puede tener conciencia de una ausencia"4. Y como tomar consciencia es dar sentido, nos sentimos habilitados a echar anclas y comenzar desde allí a pensar lo unseeable, desde su cercanía con la ausencia. Dedicaremos a ello la sección 3. En la sección 4 estudiaremos la imagen en relación con lo invisible, la formación de la imagen y su reconstrucción. En la sección 5 extenderemos al dominio del tiempo la ausencia que lo unseeable le impone al espacio-tiempo en el que es.

\section{El espaciotiempo, el objeto, su ausencia}

Comencemos con una pregunta de rigor: ¿Existe un objeto tal? ¿Existen en la naturaleza entes cuya invisibilidad extrema someta al espacio en el que el fenómeno es a estar ausente, que condene al tiempo en el cual el fenómeno es a cesar? Luego, ¿cómo pensar la ausencia del tóroc sin que el fenómeno se desvanezca al hacerlo?; ¿cómo pensar el fenómeno sin tiempo?

Comencemos respondiendo la primera de estas preguntas: Esos entes existen. Son objetos astronómicos que son la misma ausencia del espacio que ocupan; astros en cuya superficie el tiempo se encuentra detenido; materia-energía encerrada tras sus propios horizontes: sus horizontes internos, los infinitos escorzos no vistos, que en este caso son todos, y sus horizontes externos, que son lo único por lo cual inferimos su presencia, su entorno singular, su relación con lo circundante, la huella del espacio que vacían. Se los conoce como agujeros negros, objetos silentes que pueblan el cosmos sin que sepamos necesariamente de ellos; objetos que son en un espacio que no es y que, aun así, se dan al fenómeno.

4. Cfr. Sartre (1996, p. 29), quien se expresa asíal analizar las (dos) acepciones de la afirmación "toda conciencia es conciencia de algo".

Umática. 2020; 3:15-29 
Durante unos pocos días de abril de 2017, cerca de una decena de telescopios distribuidos alrededor del planeta se dispusieron a observar simultáneamente un intrigante punto en el cielo, en el corazón de la galaxia lejana llamada Messier 87 (M87). Dos años después, el 10 de abril de 2019, en conferencia de prensa simultánea alrededor del mundo, Sheperd Doeleman, astrónomo del Centro de Astrofísica de la Universidad de Harvard, anunciaba su hallazgo: "We have seen what we thought it was unseeable" (Cfr. Akiyama K., 2019), hemos visto lo que creímos que era imposible de ser visto. Lo que Doeleman y sus colaboradores habían observado era la primera imagen de un agujero negro; la imagen de un objeto cuya existencia había sido predicha por la teoría y que, por definición, es imposible de ser visto. Habían observado la silueta del horizonte de ese astro invisible recortada sobre el fondo de luz que lo envuelve. Decía Levinas (2006, p. 41): "[a] partir del ser, a partir del horizonte luminoso en el que el ente tiene una silueta pero ha perdido su cara, éste es la llamada misma dirigida a la inteligencia".

Pero, antes de continuar, y a efectos de dimensionar mejor la naturaleza peculiar de aquello de lo que estamos hablamos, dediquemos unos párrafos a explicar qué son los agujeros negros: Se trata de objetos predichos por la teoría de la relatividad general de Einstein. Esta teoría, formulada en 1915, lleva a repensar la interacción gravitatoria entre los cuerpos, ya no en términos de una fuerza, sino en términos de la curvatura del espacio mismo. Desde Einstein, la gravedad no es concebida como una fuerza entre los cuerpos sino como un efecto de la forma no-euclidiana que el espacio-tiempo adopta entre éstos. Un ente (e.g. un astro) no atrae a los otros porque actúen entre ellos fuerzas en el sentido newtoniano, sino porque cada uno de los entes (los astros) curva el espacio-tiempo en sus inmediaciones sometiendo a los otros a ceñir sus trayectorias a dicha curvatura. A esto se debe que comúnmente se diga que la teoría de la relatividad cumple con poner de manifiesto la naturaleza dinámica del entramado espacio-temporal.

Cuanto mayor es la densidad de materia-energía concentrada en el ente gravitantepensemos por caso en un astro muy denso-, mayor será el campo gravitatorio en su cercanía o, en términos einsteinianos, mayor será la curvatura del espacio-tiempo en sus inmediaciones. Pero sepamos que esta curvatura tiene un límite: Si la densidad de materia-energía del ente gravitante excede cierto valor, entonces el exceso de curvatura termina por desgarrar el tejido espacio-temporal, recortando el espacio en torno al ente. Se forma así un agujero negro: un bocado arrancado al espacio mismo; una reducida región del espacio de la cual nada puede salir; un volumen que contiene aquello de lo que nada nos puede ser restituido; un espacio interior desconectado causalmente de su exterior, de nosotros, de todo fenómeno.

Debido a esta desconexión causal absoluta y eterna entre los procesos internos y los externos, no es inexacto decir que, desde el punto de vista de toda con-ciencia externa, el espacio-tiempo, entendido éste como el escenario en el que se dan los fenómenos, se recorta allí, en la superficie de los agujeros negros, en la denominada "superficie de eventos"; allí termina. A ningún proceso interno le es dado estar en correlación con un fenómeno en el mundo exterior. Así, antes que astros, estos entes pueden ser pensados como hoyos en el espacio-tiem- 
po, ausencias del espacio en donde ellos son ${ }^{5}$. Nada puede escapar de su interior; ningún tipo de luz, ni materia, ni radiación; ningún proceso interno puede ser causa de los procesos que ocurran afuera; no hay forma en la que la constitución interior pueda afectar lo externo; puede penetrárselos mas no atravesárselos; no hay experiencia sensible que provenga de lo que allí adentro existe. Ni siquiera la luz puede dejar el objeto debido a su gravedad extrema, i.e. a su curvatura extrema. El objeto, el astro, se torna así invisible en el sentido más fuerte que al término "invisible" le haya sido otorgado en disciplina científica alguna: the unsseable. Ya decíamos: No se trata aquí de la física de lo invisible, sino de lo invisible en la física.

Pero, antes de continuar, y dado que hablamos aquí de entes que hacen al mundo de las ciencias físicas, valga una advertencia de carácter metodológico: Los ejemplos provistos por éste y por otros descubrimientos de la física y la astronomía nos tientan hacia la actitud natural y nos invitan a aceptar de manera cuasi axiomática que los entes con los que uno trata en efecto existen, que son parte del mundo físico, de la naturaleza. No obstante, aunque su existencia es, adelantamos, algo sobre lo que concluiremos de manera afirmativa, no queremos apresurar tal conclusión sin antes plantear algunas cuestiones preliminares; no queremos, como diría Husserl, pecar de ingenuos: "[T]oda ciencia de la naturaleza es ingenua. La naturaleza que ella pretende estudiar existe simplemente. Se sobreentiende que las cosas son, que cambian en el espacio infinito, y como cosas temporales en el tiempo infinito. Las percibimos, las describimos en simples juicios de experiencia" (2013a, p. 53). En palabras de Heidegger, "La investigación científica destaca y fija los dominios de cosas de una manera ingenua y rudimentaria" (1993, p. 18). Según Husserl, corresponde a una fenomenología de la naturaleza someter a una investigación esencial la conciencia constituyente de la naturaleza en todas sus estructuras y correlaciones, en forma tal que lleguen a esclarecerse todos los principios bajo los cuales hay a priori ser en el sentido de la naturaleza ${ }^{6}$. Es así como debemos, decíamos ya, plantear algunas cuestiones preliminares antes de pronunciarnos sobre la existencia de la naturaleza que pretendemos estudiar. Algunas de estas cuestiones son: la pregunta sobre la ausencia [del espacio] como fenómeno; la relación entre la silueta, los horizontes y la imagen; la relación entre los horizontes y lo invisible. Comencemos analizando con mayor profundidad la ausencia como fenómeno. A esto dedicaremos la próxima sección.

\section{La ausencia y la fenomenología de lo invisible}

Tratamos con entes constituidos tan solo por sus horizontes. El espacio que ocupan, decíamos, está ausente. No son en el espacio?. Existe, sin embargo, esa ausencia, la del espacio, y es a esa ausencia a la que debemos dirigir la mirada y a la que debemos dar sentido.

5. Son también "ausencia del tiempo" en donde ellos son, como veremos más adelante al hablar del "objeto teleológico".

6. Expresado en una carta de Husserl a Wilhelm Dilthey fechada el 5-6 de julio de 1911, cuya copia incompleta se conserva en el Archivo Husserl, de Lovaina.

7. Y así como no son en el espacio, no son en el tiempo. Discutiremos esto en la sección IV.

Umática. 2020; 3:15-29 
Esta tarea plantea una serie de preguntas iniciales antes del abordaje fenomenológico: Si ser consciente es dar sentido y dar sentido involucra completar lo que falta, ¿cómo entender "lo que falta" en el caso de un objeto que es sólo horizontes? ¿Cómo funciona el método cuando lo que falta es todo lo dado? Esto es, ¿cómo nos enfrentamos al problema de la ausencia general del campo de sensación? ¿Cómo funciona la correlación en tal caso? ¿Puede, no digamos ya definirse con precisión, pero al menos intuirse el campo hylético si "la cosa" no existe en el espacio, o existe en un lugar en el que el espacio no es como tal?

Para abordar estas preguntas, primero debemos pensar en la ausencia como fenómeno para que nos sirva de guía: El espacio que el astro ocupa no existe. No existe debido a la gravedad del astro mismo, que lo hunde en ausencia. Pero esa ausencia sí existe. Esa ausencia es el fenómeno. $Y$ de ninguna manera debemos temer a pensar en la aparición del objeto, en el fenómeno, como mediado por la observación de la ausencia. Después de todo, ver un objeto es, siempre, ver lo que el objeto rechaza: Algo es azul cuando es el azul el único color que "lo observado" no adquiere, el único que no logra sintetizar, que no absorbe. En términos ontológicos, en la observación, el particular objeto azul se constituye a partir de la reluctancia del universal azul. Eso encausa el análisis y permite pensar a todo acto de observación como un acto reconstructivo, como un acto de completación. Después de todo, como decía Levinas (2016, p. 212), "[v]er es, pues, ver el horizonte."

Tampoco debemos temer a pensar al acto de observación como ligado al espacio vacío. Dice también Levinas (ibid., p. 40) que "iluminar es quitar al ser su resistencia, porque la luz abre un horizonte y vacía el espacio". En términos más precisos (ibid., p. 210): "La luz hace aparecer la cosa expulsando las tinieblas: vacía el espacio. Hace surgir, precisamente, el espacio como un vacío." Debemos pensar así a ese espacio vacío: Una ausencia que excluye lo otro, todo otro ser ahí; una ausencia errante, propagante, por cuanto el movimiento del astro arrastra consigo esa ausencia del espacio en el que es. Luego, esa ausencia es fenómeno a través de sus horizontes externos: La gravedad en las inmediaciones de ese espacio vaciado (de espacio) afecta a la materia circundante, genera su acreción, la arremolina, la calienta, la ioniza, la expulsa; somete incluso a la luz rasante torciendo su trayectoria y dándole tintes impropios. Uno observa todo eso, los efectos sobre lo circundante, sus horizontes externos. Así, el objeto, la ausencia del espacio, aparece. Aparece a través de las cosas vistas, de la materia arremolinada y del borde filoso en el que ese arremolinarse termina para dar paso al abismo. Nuevamente recordamos a Levinas (2016, p. 211):

Pero este vacío espacial ¿no es a su vez 'alguna cosa', la forma de toda experiencia, el objeto de la geometría, algo visto? De hecho, hay que pintar un trazo para ver la línea. Sea cual sea la significación del paso al límite, las nociones de la geometría intuitiva se impondrán a partir de las cosas vistas: la línea es el límite de una cosa; el plano, la superficie de un objeto. 
El espacio ausente "es el límite" de todo fenómeno circundante. Su inexistencia aparece por contraste frente todo lo que allí ocurre, todo arremolinarse y calentarse y cambiar de color. Se recorta sobre ese fondo tumultuoso una silueta oscura que sugiere la presencia del abismo, del espacio ausente:

El ojo no ve la luz, sino el objeto en la luz. La visión es, pues, una relación con un 'algo', con 'alguna cosa', que se establece en el seno de una relación con lo que no es un 'algo', con lo que no es 'alguna cosa'. Estamos en la luz en la medida en que nos encontramos la cosa en la nada. (Levinas, 2016, p. 211).

O la nada en la cosa.

Resumiendo, el ente gravitante es en un espacio que está ausente, y de esa ausencia se puede tener consciencia, se da al fenómeno; el fenómeno se da a través de sus horizontes externos, de su afección sobre lo circundante. Esa ausencia, por otra parte, es una ausencia dinámica, propagante; se mueve arrastrada por el gravitante.

Pero, antes de continuar, y tal como hicimos con las categorías de lo invisible, ensayemos una tipificación, aunque sea parcial, de las ausencias. Esto nos permitirá, por un lado, precisar la definición del término y, por el otro, preparar el terreno para discutir la relación entre la ausencia y la imagen. Partamos diciendo que la ausencia es siempre ausencia de algo. Hay una intencionalidad que actúa ahí. Una segunda observación es acerca de la necesidad de distinguir la ausencia de la vacancia: La ausencia no es vacancia. La intencionalidad está presente con mayor fuerza en la ausencia. Aunque la vacancia también es pensada en el sentido de algo, se trata de un "para algo" con multiplicidad, abierto. La ausencia, por su parte, está dirigida al objeto que falta con mayor fuerza. Hay una especificidad en la ausencia que logra potenciarla.

La ausencia puede estar dirigida al objeto faltante de diferentes maneras: puede estar dirigida directamente hacia algo que estuvo o que fue; puede ser también ausencia de carácter subjuntivo, en relación de lo que pudo haber sido-habido; puede la intencionalidad estar donada por formas como "lo aún ausente", "lo ya ausente", "lo siempre ausente". Sin ánimo de que esta caracterización resulte ser exhaustiva, podemos resumir las formas principales de la ausencia como la de "lo inexistente", la de "lo ausente propiamente dicho", la de "lo existente en otro lugar-tiempo". En la próxima sección discutiremos la ausencia en relación con la imagen y veremos la relación entre estas formas de la ausencia y las formas que, según Sartre, el acto de creencia que la imagen encierra puede adoptar.

\section{Sobre la imagen y su horizonte}

En 2019 Peter Galison obsequia al Museum of Modern Art (MoMA) una fotografía de la imagen del agujero negro supermasivo en el centro de la galaxia M87 en representación de la Event Horizon Telescope Collaboration. El Departamento de Fotografía del MoMA la in- 
corpora a su colección ese mismo año. La imagen de la ausencia, del espaciotiempo ausente, reificada.

Comencemos por entender la relación entre la imagen y el objeto "invisible" del que hablamos. Para comprender esta relación debemos primero discutir dos aspectos fundamentales del acto de observación: la formación de la imagen y su reconstrucción. Hablaremos primero de la formación de la imagen, de los procesos involucrados y del papel particularmente activo que desempeña el observado en la generación de la forma de lo observado. Luego, discutiremos sobre el proceso de adquisición y re-construcción de la imagen.

La imagen del agujero negro es la imagen de su silueta, que no es la de su sombra proyectada sobre otro astro sino los bordes de luz que dibujan su contorno sobre la materia incandescente que lo rodea. Pero el papel desempeñado por el ente observado en el proceso de formación de la imagen no es pasivo: el objeto no se limita a donar su forma. Por el contrario, en cuanto ente gravitante, el astro moldea su forma; afecta la trayectoria de la luz en sus inmediaciones y produce la deflexión de los rayos de luz que nos traen su imagen. Por eso adelantábamos que el observado desempeña un papel particularmente activo en la generación de la forma observada. Esa silueta es la silueta del astro, del espacio que ocupa, que decíamos ausente, pero es a la vez una de-formación de dicha silueta debida a su propia gravedad. Decimos entonces que la "forma pura" y "la forma observada" no necesariamente coinciden, y que es la gravedad del ente mismo la razón de esa discrepancia. La materia se arremolina en torno al astro gravitante, se acerca a él sometiéndose a fricciones enormes debido a lo reducido del volumen que ocupa. Esa fricción eleva la temperatura de la materia hasta producir su desmembramiento, su ionización y, con ello, su incandescencia. El astro, aunque invisible, aparece así recortado en el fondo generado por una luz que lo envuelve, y que lo envuelve en el sentido más cabal del término: la luz lo orbita. El astro gravitante le impone a esa luz envolvente cambios de tono que le son impropios y, así, una cromaticidad anómala se convierte también en evidencia de su presencia. Otros efectos se suman a los anteriores: La rotación del astro le otorga impulso a la luz en la dirección de su giro, diferenciando así el color los rayos de luz co-rotantes del de los contra-rotantes. Esto, asimismo, produce una deformación adicional de la silueta, dotándola de una forma nefroidal.

¿Cuál es la forma del astro, entonces? ¿Es su forma, acaso, una forma original que uno reconstruiría luego de restar los efectos distorsivos que la gravedad del astro mismo ejerce sobre la luz? ¿Es esa forma pura, depurada, reconstruida, la forma del astro o, por el contrario, no es la forma de nada existente? ¿Puede esa reconstrucción ser pensada como un acto de completación? Las respuestas a estas preguntas se han dado ya. Alcanza con recordar nuevamente que ver el color es siempre ver el color que el objeto rechaza y aún se trata de su color. La forma es la del fenómeno, con la suma de los efectos "distorsivos" por cuanto son ésos inescindibles, inextirpables del ente.

Luego está la reconstrucción de la imagen, que en el caso de la imagen del agujero negro merece especial atención debido a que, más que en cualquier otra observación visual jamás llevada a cabo por el hombre, los efectos lumínicos nos llegan fragmentados. Toda imagen es 


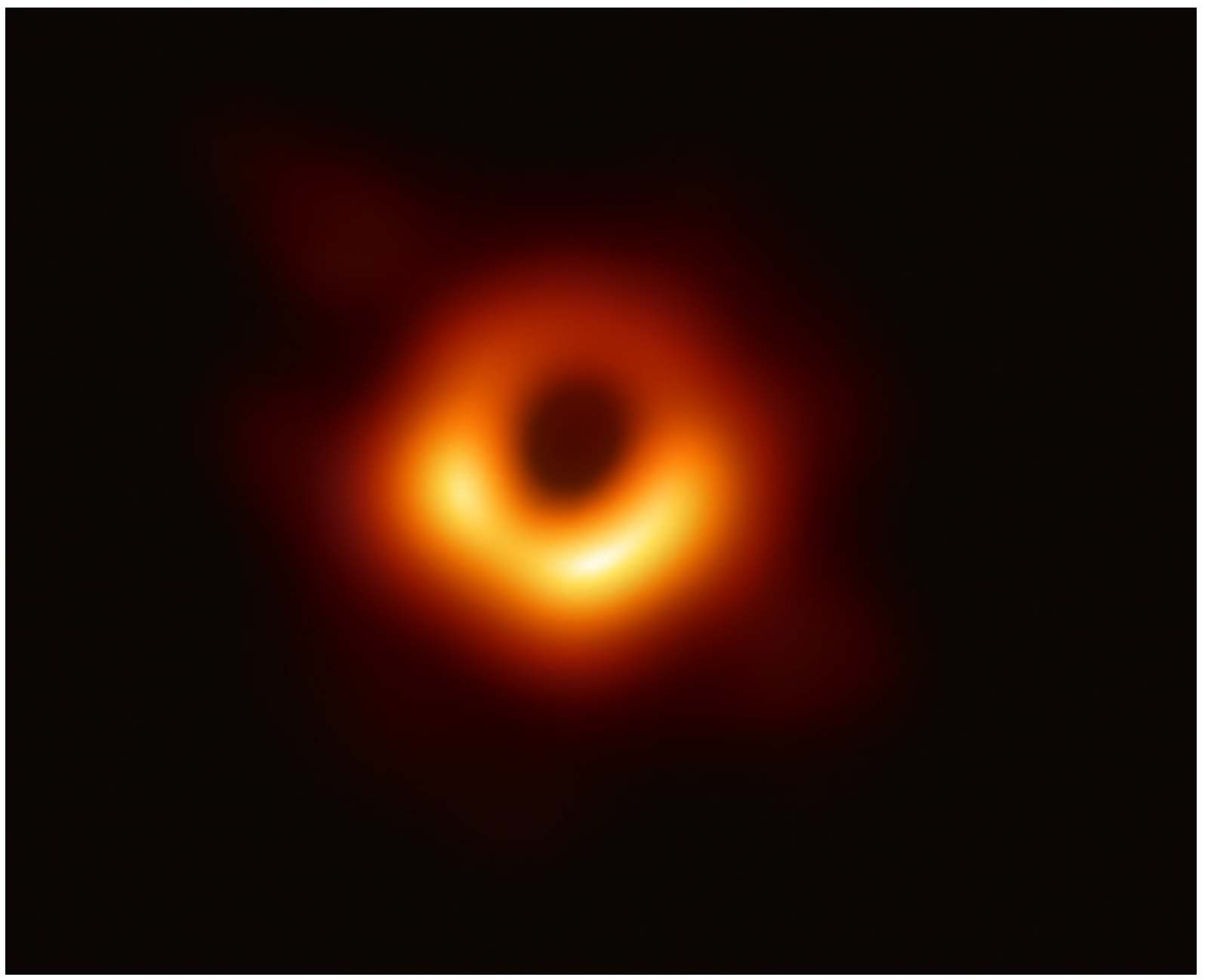

composición de fragmentos, de elementos mínimos, irreducibles: los centenares de millones de células de nuestras retinas, los diminutos capacitores constituyentes de las cámaras digitales, el haluro de plata de las películas fotográficas; el grano; el píxel; lo irreducible; lo que está por debajo de las células de sentido. El acto de composición nace de la eliminación de esa naturaleza granular al dar sentido. La imagen es, siempre, composición de partes y es, a su vez, la anulación de esas partes. Podemos decir de manera sintética que el hecho de que la imagen se dé lleva en germen el acto de dejar de lado lo irreducible.

En el caso de la imagen de la silueta del agujero negro tomada por Doeleman et al. los elementos irreducibles adquieren tamaños enormes. El astro se encuentra en una galaxia lejana, separada de la nuestra por decenas de millones de años luz. Tratándose de una región reducida del cielo que se encuentra tan lejos de nosotros, la amplitud angular de lo observado resulta ser extremadamente pequeña, comparable a la exigencia de ver una pequeña roca en la superficie lunar. Esto lleva en germen una dificultad a la hora de la observación: Debido a la naturaleza ondulatoria de la luz, toda imagen tan pequeña será borrosa. Sólo un telescopio del tamaño de nuestro planeta lograría una imagen de la calidad necesaria para ver la
Imagen del agujero negro M87*. Crédito: The Event Horizon Telescope Collaboration. 
silueta buscada. Así, Doeleman et al. convirtieron a la Tierra en un enorme telescopio virtual: recurrieron a una serie de observaciones independientes, realizadas simultáneamente por varios telescopios emplazados en distintas partes del globo; en California, Atacama, Hawái, Europa, el polo sur. Esas imágenes se combinaron gracias a una tarea minuciosa de sincronización y procesamiento, convirtiendo al planeta en una cámara, en una gran retina. Así, la imagen de la silueta aparece, como toda imagen, en un acto de reconstrucción.

Se tiene así la imagen reconstruida de la silueta, silueta que es la forma del astro pero que es, a su vez, una forma deformada, el resultado de la perturbación gravitacional que el ente observado ejerce sobre la luz que nos trae su propia imagen. El ente gravitante afecta a la luz que lo envuelve y moldea su propia forma recortada sobre esa luz. Esa forma se reconstruye mediante la asociación de distintas proto-imágenes, tomadas éstas por diferentes telescopios alrededor del mundo. Cada una de esas proto-imágenes es una mancha borrosa y no la silueta; sólo en la unión de esas proto-imágenes el objeto aparece: Aparece ese negro no existir del espacio dibujado sobre un ambiente violento, luminoso y distorsionado.

Es oportuno detenernos aquí para repensar la imagen en relación con el objeto; repensar la imagen, la silueta y la donación de sentido a partir de ellas. Como escribió Barthes (2019, p. 50), "[e]n esta búsqueda de la Fotografía, la fenomenología me prestaba, pues, un poco de su proyecto y un poco de su lenguaje."

Sartre (2005, p. 15) se preguntaba:

¿Y qué es exactamente la imagen? Evidentemente, no es [el objeto]; de una manera general, el objeto de la imagen no es imagen a su vez. ¿Diremos que la imagen es la organización sintética total, la conciencia? Pero esta conciencia es una naturaleza actual y concreta, que existe en sí, por sí y que siempre se podrá entregar sin intermediario a la reflexión. La palabra imagen no podría, pues, designar más que la relación de la conciencia con el objeto; dicho en otras palabras, es una manera determinada que tiene el objeto de aparecer a la conciencia, o, si se prefiere, una determinada manera que tiene la conciencia de darse un objeto. [...] recordemos aquí que una imagen no es más que una relación.

Y ya que hablamos de Sartre y la pregunta ontológica dirigida a la imagen, hagamos notar las resonancias que encontramos entre la tipificación de las ausencias discutidas en la sección 3 y las formas que, según Sartre, puede tomar el acto posicional que la imagen encierra (2005, p. 23). Dice:

"Toda conciencia propone su objeto, pero cada una tiene su manera de hacerlo. La percepción, por ejemplo, propone su objeto como existiendo. La imagen encierra a su vez un acto de creencia o acto posicional. Este acto puede tomar cuatro formas, y sólo cuatro: puede proponer el objeto como inexistente, 
o como ausente, o como existente en otro lugar; también se puede 'neutralizar', es decir, no proponer su objeto como existente. [...] [La] posición de ausencia o de inexistencia no se puede encontrar sino en el plano de la cuasi-observación." (Sartre, 2005, pp. 23-24).

Habíamos concluido para la ausencia algo similar: Las formas principales de la ausencia son la de lo inexistente, la de lo propiamente ausente, y la de lo presente en otro tiempo-lugar. La ausencia y la imagen no son sólo análogas, sino inescindibles. Se necesitan mutuamente para existir. Por un lado, la imagen, para constituirse, requiere de la reconducción de la mirada hacia fuera del objeto representado; por otro lado, la ausencia necesita de imágenes del ente ausente para ser. En el caso del agujero negro, la silueta es la imagen. Toda imagen de lo verdaderamente invisible es imagen de sus horizontes externos. En este caso, la imagen de la ausencia del espacio en el que el astro es, una ausencia gravitante de la que sólo se sabe a través de la perturbación de su entorno. Ese vacío sólo puede ser silueta [esa ausencia sólo puede ser imagen]. Esa silueta sólo puede ser vacío [esa imagen sólo puede ser ausencia].

\section{El objeto teleológico}

Hablemos ahora del tiempo. Decíamos que los agujeros negros pueden ser pensados como hoyos en el espacio-tiempo, que implica la ausencia del espacio en donde ellos son, y adelantábamos que son, también, "ausencia del tiempo" en donde ellos son. La teoría de la relatividad reserva para el tiempo un lugar similar al del espacio. Esto no significa en absoluto que tiempo y espacio sean lo mismo según la teoría, pero sí que uno entra en las ecuaciones de manera entrelazada con el otro; tiempo y espacio son inextirpables. Así, si la gravedad es curvatura del espacio, entonces debe ésta ser también curvatura del tiempo en algún sentido. Y, en efecto, esto es así: el tiempo transcurre más lento en las regiones del espacio donde la gravedad es más intensa. A escalas terrestres, este letargo temporal debido a la gravedad es casi imperceptible; pero, cerca de entes de gran gravedad, se trata de un efecto dominante: En las inmediaciones de los agujeros negros, este efecto es extremo y el tiempo, literalmente, se detiene.

Esto presupone dos problemas fundamentales para nuestro análisis: por un lado, ¿cómo es posible concebir que la observación de Doeleman et al. se trate, en efecto, de la observación de un ente en el que el tiempo no existe? La temporalidad debe ser replanteada, al menos en lo que hace a sus términos. La imagen de lo invisible es, también, la imagen de lo atemporal. ¿Cómo se da el fenómeno?, ¿cómo tomar consciencia de esa atemporalidad y, con ello, darle sentido? Por otro lado, si el tiempo en las inmediaciones de los agujeros negros se aletarga al límite de que termina por detenerse en su superficie, ¿cómo entender el no-tiempo de lo allí observado?

Los agujeros negros nacen tras la muerte de ciertas estrellas. Se trata de estrellas moribundas que, habiendo agotado ya su combustible nuclear, colapsan por efectos de su pro- 
pia gravedad dando origen a esos astros densos e invisibles. Luego, el transcurrir del tiempo en la superficie de esos astros cesa, lo que plantea una paradoja zenónica: Si el tiempo no transcurre en el horizonte de los agujeros negros, el colapso de la estrella progenitora jamás termina de ocurrir. El material de la estrella iría deteniéndose en el tiempo conforme colapsa, dado que la formación del agujero negro detiene el tiempo en el que él nace. Se trata, así, de un comportamiento asintótico, un evento que se anticipa y acerca continuamente mas nunca termina de acaecer. La existencia del "agujero negro que la estrella será" sólo ocurre en el tiempo infinito, en el futuro remoto. El agujero negro es, así, un objeto teleológico, en el sentido de que todo cuanto puede decirse de él es en el futuro, en y para el fin: El horizonte nunca es. Siempre será. Nunca llega a existir. Existe sólo en el tiempo infinito. La ausencia del espacio sólo es accesible al espacio ausente y no así al observador exterior, salvo en el futuro remoto. Recordamos una vez más las palabras de Levinas: "Un aún no más lejano que un porvenir, un aún no temporal y que da testimonio de grados en la nada" (2016, p. 299).

La luz expresa el paso del tiempo mediante su color. El color es la frecuencia de su oscilar. Así, la coloración anómala de la luz proveniente de las inmediaciones del astro, del ente gravitante, nos permite dar sentido a esa detención del tiempo. Este dar sentido es adelantarse a la existencia venidera de un objeto que aún no es. Es el acto de presentificación del objeto teleológico. El tiempo detenido es, así, fenómeno. Se toma consciencia de él a través de la imagen de un objeto invisible y sin tiempo, un objeto que (aún no) es en un espacio que está ausente. Debe la fenomenología esforzarse para extender sus dominios y lograr aprehender este tipo de fenómenos. Después de todo, "la tarea que se propone el filósofo [...] consiste en alcanzar una ciencia universal del mundo, un saber universal, definitivo, una totalidad de las verdades en sí sobre el mundo, sobre el mundo en sí" (Husserl, 2013a, p. 103), y, como hoy nos es dado saber, lo invisible es parte del mundo. 


\section{Referencias bibliográficas}

AKIYAMA, K., et al. (2019). Astrophys. J. Lett. 875, L1, pp. 1-17.

https://iopscience.iop.org/article/10.3847/2041-8213/aboec7

ARISTÓTELES (1982). Física. Gredos.

BARTHES, B. (2019). La cámara lúcida.Paidós.

DELEUZE, G. (2007). Pintura. El concepto de diagrama. Cactus.

DERRIDA, J. (2000). Dar la muerte. Paidós.

GROSSETESTE, R. (1972). Summa physicorum [texto latino]. Eudeba.

HERNÁNDEZ-NAVARRO, M. (2012). El archivo escotómico de la modernidad. Alcobendas.

HEIDEGGER, M. (1993). El ser y el tiempo. Fondo de Cultura Económica.

HenRY, M. (2008). Ver lo invisible. Sobre Kandinsky. Siruela.

HUSSERL, E. (2013a). La filosofía como ciencia estricta. Prometeo.

HUSSERL, E. (2013b). La filosofía en la crisis de la humanidad europea. Prometeo.

HUSSERL ,E. (2014). Fenomenología de la conciencia inmanente del tiempo. Prometeo.

KANDINSKY, V. (1987). El futuro de la pintura. Paidós.

KAPLAN, A. (2015). Artistas de lo invisible. Antroposófica.

LEVINAS, E. (2016). Totalidad e infinito. Sigueme.

PLATÓN (1996). Teetetes, o de la ciencia. CS Ed.

SARTRE, J. P. (1996). El ser y la nada. Altaya.

SARTRE, J. P. (2005). Lo imaginario. Losada. 